Article

\title{
Synthesis and Structure-Activity Relationships of (-)-cis-N-Normetazocine-Based LP1 Derivatives
}

\author{
Lorella Pasquinucci ${ }^{1}$ (D), Carmela Parenti ${ }^{2}$, Emanuele Amata ${ }^{1}$ (i), Zafiroula Georgoussi ${ }^{3}$, \\ Paschalina Pallaki ${ }^{3}$, Valeria Camarda ${ }^{4}$, Girolamo Calò ${ }^{4}$, Emanuela Arena ${ }^{1}$, \\ Lucia Montenegro 5 (i) and Rita Turnaturi ${ }^{1, *}$ (D) \\ 1 Department of Drug Sciences, Medicinal Chemistry Section, University of Catania, Viale A. Doria 6, \\ 95125 Catania, Italy; lpasquin@unict.it (L.P.); eamata@unict.it or emanuela.arena@unict.it (E.A.) \\ 2 Department of Drug Sciences, Pharmacology and Toxicology Section, University of Catania, Viale A. Doria 6, \\ 95125 Catania, Italy; cparenti@unict.it \\ 3 Laboratory of Cellular Signaling and Molecular Pharmacology, Institute of Biosciences and Applications, \\ National Centre for Scientific Research “Demokritos” Agia Paraskevi-Attikis, 15310 Athens, Greece; \\ iro@bio.demokritos.gr (Z.G.); ppallaki@bio.demokritos.gr (P.P.) \\ 4 Department of Medical Sciences, Section of Pharmacology, University of Ferrara, via Fossato di Mortara 19, \\ 44121 Ferrara, Italy; v.camarda@unife.it (V.C.); clg@unife.it (G.C.) \\ 5 Department of Drug Sciences, Pharmaceutical Technology Section, University of Catania, Viale A. Doria 6, \\ 95125 Catania, Italy; lmontene@unict.it \\ * Correspondence: rita.turnaturi@unict.it; Tel.: +39-095-738-4273
}

Received: 16 April 2018; Accepted: 3 May 2018; Published: 5 May 2018

check for updates

\begin{abstract}
N-Normetazocine represents a rigid scaffold able to mimic the tyramine moiety of endogenous opioid peptides, and the introduction of different $N$-substituents influences affinity and efficacy of respective ligands at MOR (mu opioid receptor), DOR (delta opioid receptor), and KOR (kappa opioid receptor). We have previously identified LP1, a MOR/DOR multitarget opioid ligand, with an $N$-phenylpropanamido substituent linked to (-)-cis-N-Normetazocine scaffold. Herein, we report the synthesis, competition binding and calcium mobilization assays of new compounds 10-16 that differ from LP1 by the nature of the $N$-substituent. In radioligand binding experiments, the compounds 10-13, featured by an electron-withdrawing or electron-donating group in the para position of phenyl ring, displayed improved affinity for $\mathrm{KOR}\left(\mathrm{K}_{\mathrm{i}}=0.85-4.80 \mu \mathrm{M}\right)$ in comparison to LP1 $(7.5 \mu \mathrm{M})$. On the contrary, their MOR and DOR affinities were worse $\left(\mathrm{K}_{\mathrm{i}}=0.18-0.28 \mu \mathrm{M}\right.$ and $K_{i}=0.38-1.10 \mu \mathrm{M}$, respectively) with respect to LP1 values $\left(K_{i}=0.049\right.$ and $\left.0.033 \mu M\right)$. Analogous trends was recorded for the compounds 14-16, featured by indoline, tetrahydroquinoline, and diphenylamine functionalities in the $N$-substituent. In calcium mobilization assays, the compound $\mathbf{1 0}$ with a $p$-fluorophenyl in the $N$-substituent shared the functional profile of LP1 $\left(\mathrm{pEC}_{50}{ }^{\mathrm{MOR}}=7.01\right)$, although it was less active. Moreover, the $p$-methyl- (11) and $p$-cyano- (12) substituted compounds resulted in MOR partial agonists and DOR/KOR antagonists. By contrast, the derivatives 13-15 resulted as MOR antagonists, and the derivative 16 as a $\mathrm{MOR} / \mathrm{KOR}$ antagonist $\left(\mathrm{pK}_{\mathrm{B}}{ }^{\mathrm{MOR}}=6.12\right.$ and $\left.\mathrm{pK}_{\mathrm{B}}{ }^{\mathrm{KOR}}=6.11\right)$. Collectively, these data corroborated the critical role of the $N$-substituent in (-)-cis-N-Normetazocine scaffold. Thus, the new synthesized compounds could represent a template to achieve a specific agonist, antagonist, or mixed agonist/antagonist functional profile.
\end{abstract}

Keywords: opioid receptors; radioligand binding; calcium mobilization; benzomorphan

\section{Introduction}

Natural, semi-synthetic, and synthetic opioid ligands [1-4], featured with different structural scaffolds, exert their action following recognition of three different opioid receptors, namely mu, 
delta, and kappa opioid receptors (MOR, DOR, and KOR, respectively), which are members of the large superfamily of $G$ protein coupled receptors (GPCRs) [5] that couple to Gi/o members and other proteins to regulate signaling. Endogenous ligands of these receptors are opioid peptides generally characterized by the highly conserved $\mathrm{N}$-terminal tetrapeptidic sequence Tyr-Gly-Gly-Phe [6], although the MOR-selective endogenous peptides, endomorphin-1 (EM-1, Tyr-Pro-Trp-Phe- $\mathrm{NH}_{2}$ ) and endomorphin-2 (EM-2, Tyr-Pro-Phe-Phe- $\left.\mathrm{NH}_{2}\right)$, had a different sequence [7]. (-)-cis- $\mathrm{N}$-Normetazocine, resulting from a progressive simplification of morphine skeleton, represents a rigid scaffold able to support the phenolic ring and the basic nitrogen in a conformation mimicking the tyramine moiety of opioid peptides [8]. In several investigations, the pivotal role of the substituent at the basic nitrogen has emerged [9-13]. Indeed, the $N$-substituent nature influences affinity, selectivity, and activity towards all three opioid receptor subtypes.

We have previously reported the synthesis and pharmacological characterization of different series of (-)-cis- $N$-normetazocine-based ligands [14]. These data demonstrated that the introduction of the acetamido spacer in the basic nitrogen was detrimental for MOR, DOR, and KOR binding. By contrast, the $N$-propanamido spacer elongation provided derivatives with an improved binding profile. Among them, LP1 ((1) (3-[(2R,6R,11R)-8-hydroxy-6,11-dimethyl-1,4,5,6-tetrahydro-2,6-methano-3benzazocin-3(2H)-yll- $N$-phenylpropanamide, Figure 1$)$, featured with a $\mathrm{N}$-phenylpropanamido substituent, resulted in high MOR and significant DOR binding coupled to a MOR/DOR agonist multitarget profile, consistent with its significant antinociceptive effect in nociceptive and persistent pain rat models [15-17]. It has also highlighted the importance in the $N$-substituent of a secondary amide for the opioid receptor interactions [14], while the presence of a tertiary amide led to poor $\mathrm{K}_{\mathrm{i}}$ values, mainly towards MOR. Moreover, the critical role of the aromatic ring in the $\mathrm{N}$-phenylpropanamido spacer was assessed. Saturated chains made worse the receptor binding interaction, although the cyclohexyl ring retained a significant MOR affinity [14]. Bulkier aromatic/heteroaromatic rings also resulted in a loss of opioid binding affinity, with the exception of the compound bearing 1-naphthyl ring in the $\mathrm{N}$-propanamido chain ((2), Figure 1) that retained MOR affinity with a high degree of selectivity. However, this bulkier substituent switched the efficacy profile from agonism to antagonism [18]. The presence of a second positive charge, as well as the shortening of the $\mathrm{N}$-substituent spacer, obtained through the insertion of secondary and tertiary ethylamino or propylamino side chains, led to benzomorphan-based compounds able to address the ligand-opioid receptor interaction, mainly at MOR and KOR [19]. Recently, we have also reported the insertion at the basic nitrogen of a shorter and more flexible ethyl spacer with H-bonding groups at carbon 2 as a successful strategy to improve MOR and DOR affinity [20].

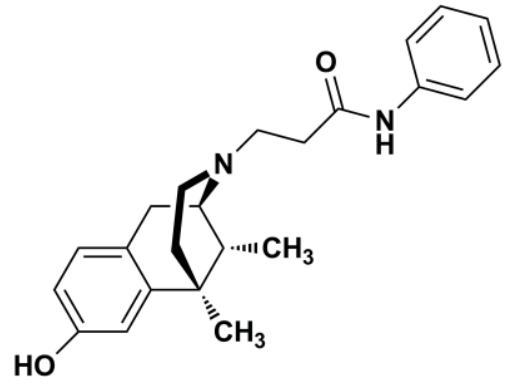

LP1 (1)

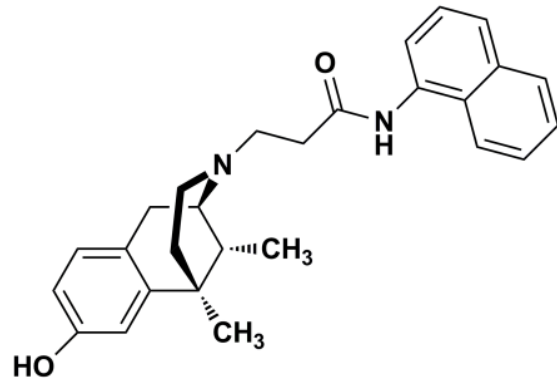

(2)

Figure 1. LP1 (1) and its N-analogue (2) structures.

In this study, we extended our structure-activity relationships (SARs) [14,18-20] and evaluated the effects of para electron-donating or -withdrawing groups insertion in the LP1 phenyl ring (10-13, Figure 2). Moreover, the employment of phenyl ring surrogates with an increased steric hindrance (using indoline, tetrahydroquinoline, and diphenylamine functionalities) in the $\mathrm{N}$-substituent (14-16, 
Figure 2) was also assessed. To determine the opioid functional profile, derivatives 10-16 were tested by radioligand competition binding and calcium mobilization assays for MOR, DOR, and KOR. Collected data corroborated the importance of the phenyl ring in the $N$-propanamido substituent of the (-)-cis-N-Normetazocine scaffold for MOR and DOR functional profile. Although all synthesized compounds, in comparison to the lead compound LP1, exhibited a worse efficacy profile, they could represent a template in the achievement of a specific functional profile, by modifying $N$-substituent electronic and steric features.
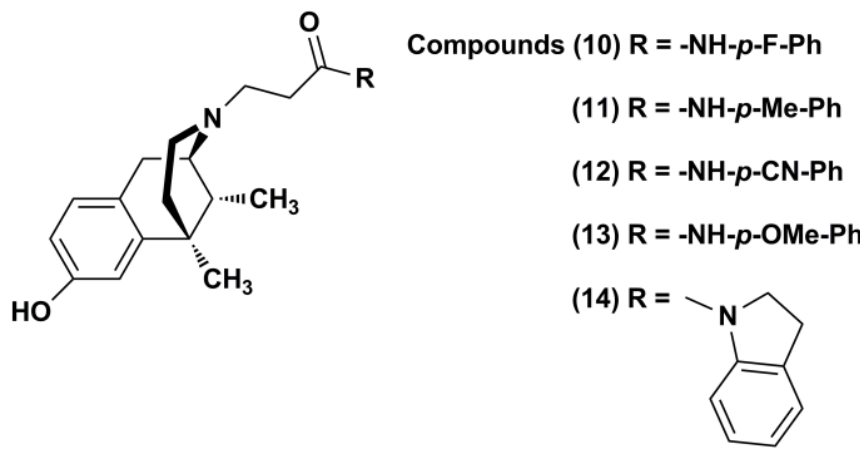

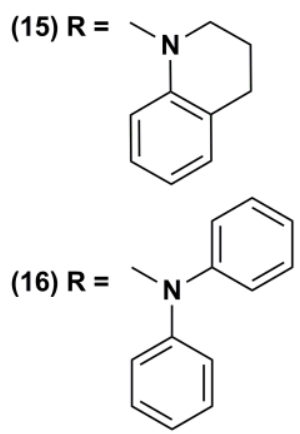

Figure 2. LP1 N-derivatives 10-16 structures.

\section{Results and Discussion}

\subsection{Chemistry}

In Scheme 1, the synthesis of the novel compounds is illustrated. Resolution of $( \pm)-c i s-N$ Normetazocine was carried as previously reported [18,21]. Briefly, amides 3-9 were prepared by acylation of the respective amines with 3-bromopropionyl chloride in anhydrous THF in argon atmosphere. The target compounds 10-16 were obtained by alkylation of (-)-cis- $(1 R, 5 R, 9 R)-N$ Normetazocine with the respective amides 3-9 in DMF. All the synthesized compounds were characterized by IR, ${ }^{1} \mathrm{H}$ NMR, ${ }^{13} \mathrm{C}$ NMR, mass spectroscopy, and elemental analysis.
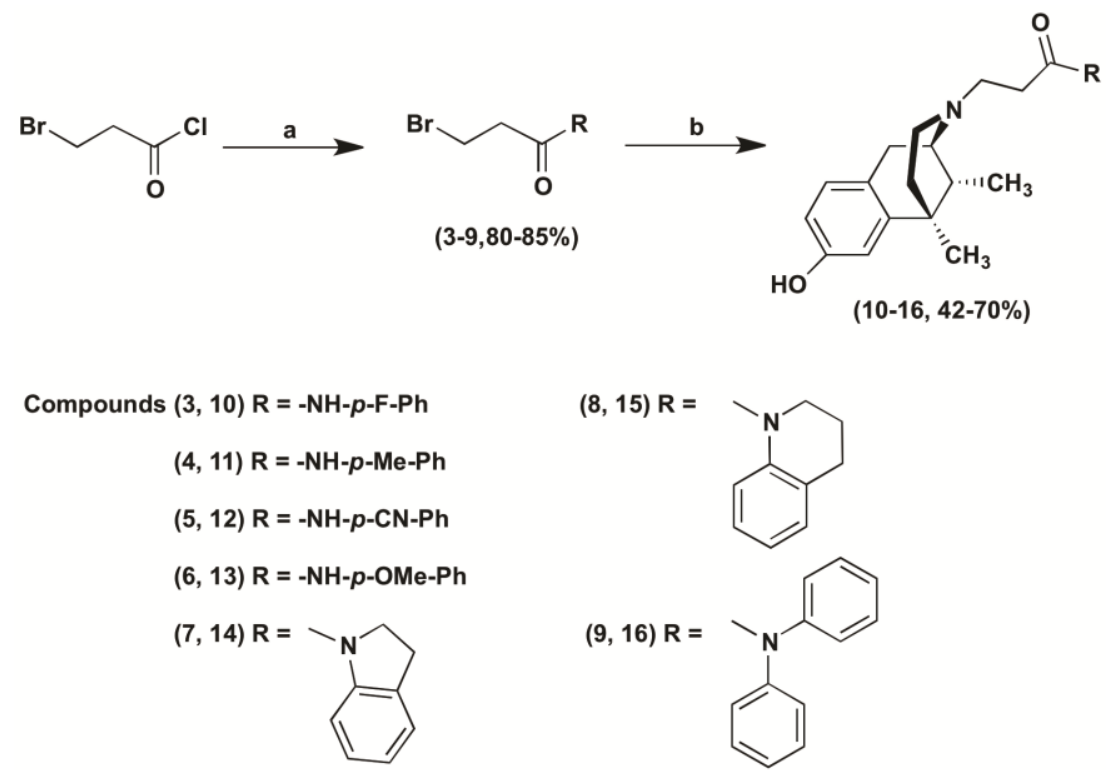

$(8,15) R=$<smiles>CN1CCCc2ccccc21</smiles>

$(9,16) \mathrm{R}=$<smiles>CN(c1ccccc1)c1ccccc1</smiles>

Reagents and conditions: a) Respective amine, DMAP, THF, $0^{\circ} \mathrm{C}, 1 \mathrm{~h}$; b) (-)-cis-(1R,5R,9R)-Nnormetazocine, $\mathrm{NaHCO}_{3}, \mathrm{KI}, \mathrm{DMF}, 50^{\circ} \mathrm{C}, 12 \mathrm{~h}$.

Scheme 1. Synthetic pathway. 


\subsection{Radioligand Binding Assay}

All synthesized compounds were tested in vitro by radioligand competition binding using $\left[{ }^{3} \mathrm{H}\right]$-diprenorphine $\left(\left[{ }^{3} \mathrm{H}\right]-\mathrm{DPN}\right)$ to measure the affinity for opioid receptor subtypes in membranes from HEK293 cells stably expressing either MOR, DOR, or KOR, as previously described [22,23]. Calculated $K_{i}$ values are listed in Table 1. In comparison to the lead LP1, compounds 10-16 displayed a decreased binding affinity for MOR and DOR, while affinity for KOR was increased.

Table 1. Opioid receptor binding affinity values of LP1, and its derivatives $\mathbf{2}$ and $\mathbf{1 0}-\mathbf{1 6 .}$

\begin{tabular}{cccc}
\hline \multirow{2}{*}{ Compound } & \multicolumn{3}{c}{$\mathbf{K}_{\mathbf{i}}(\boldsymbol{\mu M}) \pm \mathbf{S E M}^{\mathbf{a}, \mathbf{b}}$} \\
\cline { 2 - 4 } & MOR & DOR & KOR \\
\hline LP1 (1) & $0.049 \pm 0.015$ & $0.033 \pm 0.020$ & $7.500 \pm 0.015$ \\
$\mathbf{2}[18]$ & $0.038 \pm 0.004$ & $0.210 \pm 0.030$ & $0.800 \pm 0.016$ \\
$\mathbf{1 0}$ & $0.280 \pm 0.013$ & $0.920 \pm 0.120$ & $4.800 \pm 0.950$ \\
$\mathbf{1 1}$ & $0.240 \pm 0.015$ & $0.410 \pm 0.023$ & $1.010 \pm 0.110$ \\
$\mathbf{1 2}$ & $0.210 \pm 0.024$ & $0.380 \pm 0.034$ & $0.850 \pm 0.180$ \\
$\mathbf{1 3}$ & $0.180 \pm 0.011$ & $1.100 \pm 0.110$ & $4.000 \pm 0.180$ \\
$\mathbf{1 4}$ & $0.400 \pm 0.030$ & $1.400 \pm 0.120$ & $1.600 \pm 0.120$ \\
$\mathbf{1 5}$ & $0.360 \pm 0.023$ & ND & $0.200 \pm 0.020$ \\
$\mathbf{1 6}$ & $0.170 \pm 0.013$ & ND & $0.200 \pm 0.030$ \\
\hline
\end{tabular}

a Values are means \pm SEM of three separate experiments, each carried out in duplicate; ${ }^{b} K_{i}$ values were obtained as $\left[{ }^{3} \mathrm{H}\right]-\mathrm{DPN}$ displacement for MOR, DOR, and KOR; ${ }^{\mathrm{c}}$ ND not determined.

MOR $K_{i}$ values for the $p$-substituted phenyl derivatives 10-13 were six-, five-, four-, and four-times higher than LP1 $K_{i}$ values. Increased $K_{i}$ values at DOR were also recorded for compounds 10-13. In fact, DOR $K_{i}$ values for compounds 10-13 were twenty-eight-, twelve-, eleven-, and thirty-times higher than LP1 $\mathrm{K}_{\mathrm{i}}$ values. On the other hand, the KOR affinity of $p$-substituted phenyl analogues was increased. An analogous trend in receptor affinity was also reported for compounds 14-16 that displayed eight-, seven-, and three-times decreased affinity versus MOR and DOR. Notably, the KOR affinity of compounds 14-16 significantly increased, with $\mathrm{K}_{\mathrm{i}}$ values approximately five-, thirty-seven-, and thirty-seven-times lower than the LP1 $\mathrm{K}_{\mathrm{i}}$ value. These data once more underline the critical role of $\mathrm{N}$-substituent in (-)-cis-N-Normetazocine scaffold for opioid receptor binding affinity.

Tested compounds 10-16 differ from the LP1 structure by their $N$-substituent nature. In compounds 10-13, the introduction of an electron-withdrawing or electron-donating group para to the phenyl ring in the $\mathrm{N}$-phenylpropanamido chain is critical for MOR and DOR interaction, but led to an improved KOR interaction. In compounds 14-16, the phenyl ring replacement with indoline, tetrahydroquinoline, and diphenylamine functionalities was detrimental for MOR, and mainly for DOR interaction, while the KOR interaction was improved. Thus, the introduction at the $N$-substituent of a phenyl ring with different electronic and steric features significantly improve KOR interaction, but not MOR and DOR.

\subsection{Calcium Mobilization Assay}

The pharmacological characterization of LP1 derivatives $\mathbf{2}$ and 10-16 was performed by calcium mobilization assay (Table 2). This procedure was preliminarily validated through a series of experiments where the effects of DPDPE, dermorphin, and dynorphin A were assessed in CHO cells expressing the human recombinant opioid receptors and $\mathrm{G} \alpha_{\mathrm{qi} 5}$ or $\mathrm{G} \alpha_{\mathrm{qG} 66 \mathrm{Di5}}$ chimeric proteins [24]. The obtained results highlighted that all the standard compounds tested showed the expected functional profile. 
Table 2. Effects of LP1 and its derivatives $\mathbf{2}$ and $\mathbf{1 0 - 1 6}$ in CHO cells expressing G $\alpha_{\mathrm{qi} 5}$ or $\mathrm{G} \alpha_{\mathrm{qG} 66 \mathrm{Di} 5}$ chimeric $G$ protein and recombinant human opioid receptors in the calcium mobilization assay.

\begin{tabular}{|c|c|c|c|c|c|c|}
\hline \multirow[b]{2}{*}{ Compound } & \multicolumn{2}{|c|}{ MOR } & \multicolumn{2}{|c|}{ DOR } & \multicolumn{2}{|c|}{ KOR } \\
\hline & $\underset{\left(\mathrm{CL}_{95 \%}\right)^{\mathrm{a}}}{\mathrm{pEC}_{50}}$ & $\begin{array}{l}\mathrm{pK}_{\mathrm{B}}^{\mathrm{b}} \\
\left(\mathrm{CL}_{95 \%}\right)\end{array}$ & $\begin{array}{c}\mathrm{pEC}_{50} \\
\left(\mathrm{CL}_{95 \%}\right)^{\mathrm{a}}\end{array}$ & $\begin{array}{c}\mathrm{pK}_{\mathrm{B}}^{\mathrm{b}} \\
\left(\mathrm{CL} \mathrm{L}_{95 \%}\right)\end{array}$ & $\begin{array}{c}\mathrm{pEC}_{50} \\
\left(\mathrm{CL}_{95 \%}\right)^{\mathrm{a}}\end{array}$ & $\begin{array}{l}\mathrm{pK}_{\mathrm{B}}^{\mathrm{b}} \\
\left(\mathrm{CL}_{95 \%}\right)\end{array}$ \\
\hline LP1 (1) & $\begin{array}{c}7.01 \\
(6.29-7.73)\end{array}$ & $\mathrm{ND}^{\mathrm{c}}$ & $\begin{array}{c}5.95 \\
(5.39-6.51)\end{array}$ & ND & $\begin{array}{c}\mathrm{crc} \\
\text { incomplete }^{\mathrm{d}}\end{array}$ & ND \\
\hline 2 & Inactive $^{\mathrm{e}}$ & $\begin{array}{c}7.90 \\
(7.30-8.50)\end{array}$ & Inactive & $\begin{array}{c}6.78 \\
(6.15-7.41)\end{array}$ & Inactive & $\begin{array}{c}5.86 \\
(4.89-6.83)\end{array}$ \\
\hline 10 & $\begin{array}{c}5.67 \\
(4.82-6.52)\end{array}$ & ND & $\begin{array}{c}\mathrm{crc} \\
\text { incomplete }\end{array}$ & Inactive & $\begin{array}{c}\text { crc } \\
\text { incomplete }\end{array}$ & ND \\
\hline 11 & $\begin{array}{c}5.85 \\
(5.34-6.36)\end{array}$ & ND & Inactive & $\begin{array}{c}5.83 \\
(5.53-6.13)\end{array}$ & Inactive & $\begin{array}{c}5.85 \\
(5.65-6.05)\end{array}$ \\
\hline 12 & $\begin{array}{c}5.99 \\
(5.46-6.52)\end{array}$ & ND & Inactive & $\begin{array}{c}5.82 \\
(5.18-6.46)\end{array}$ & Inactive & $\begin{array}{c}5.90 \\
(5.40-6.40)\end{array}$ \\
\hline 13 & Inactive & $\begin{array}{c}6.30 \\
(5.81-6.79)\end{array}$ & Inactive & Inactive & Inactive & Inactive \\
\hline 14 & Inactive & $\begin{array}{c}5.94 \\
(5.26-6.62)\end{array}$ & Inactive & Inactive & Inactive & Inactive \\
\hline 15 & Inactive & $\begin{array}{c}5.71 \\
(4.63-6.18)\end{array}$ & Inactive & Inactive & $\begin{array}{c}6.59 \\
(6.35-6.83)\end{array}$ & ND \\
\hline 16 & Inactive & $\begin{array}{c}6.12 \\
(5.46-6.78)\end{array}$ & Inactive & Inactive & Inactive & $\begin{array}{c}6.11 \\
(5.78-6.44)\end{array}$ \\
\hline
\end{tabular}

Data are mean \pm SEM of at least five separate experiments. ${ }^{\text {a }}$ For $\mathrm{pEC} \mathrm{C}_{50}$ and $\mathrm{pK}_{\mathrm{B}}$ values, the $95 \%$ confidence limits are given in brackets; ${ }^{b}$ The antagonistic properties of these compounds were tested using dermorphin, DPDPE, and dynorphin A as agonists; ${ }^{\mathrm{C}} \mathrm{ND}$ : not determined; ${ }^{\mathrm{d}}$ incomplete concentration response curves at $10 \mu \mathrm{M} ;{ }^{\mathrm{e}}$ inactive compound at $10 \mu \mathrm{M}$.

In $\mathrm{CHO}^{\mathrm{MOR}}$ cells stably expressing the $\mathrm{G} \alpha_{\mathrm{qi} 5}$ chimeric protein, $\mathrm{LP} 1, \mathbf{1 0}, \mathbf{1 1}$, and $\mathbf{1 2}$ were able to stimulate calcium mobilization in a concentration-dependent manner, with LP1 showing the highest potency $\left(\mathrm{pEC}_{50}=7.01\right.$ and $\alpha=0.40 \pm 0.020$ ), thus resulting in a full MOR agonist, as reported elsewhere [14-16]. Compounds 10, 11, and $\mathbf{1 2}$ were, in fact, approximately ten-times less potent than LP1, and their estimated maximal effects were lower $(\alpha=0.30 \pm 0.015,0.23 \pm 0.011,0.34 \pm 0.017$, respectively). In cells expressing the $\mathrm{G} \alpha_{\mathrm{q} i 5}$ chimeric protein, but not MOR, these compounds were found completely inactive up to $10 \mu \mathrm{M}$ (data not shown). These results collectively demonstrated that compounds 10, 11, and 12 behave as MOR partial agonists.

LP1 derivatives 13-16 were not able to stimulate calcium mobilization in $\mathrm{CHO}^{\mathrm{MOR}}$ cells stably expressing the $\mathrm{G} \alpha_{\mathrm{q} i 5}$ protein. In antagonist type experiments, compounds 13-16 were capable of inhibiting the stimulatory effects induced by dermorphin, with an antagonist potency range of 5.71-6.30.

In $\mathrm{CHO}^{\mathrm{DOR}}$ cells stably expressing the $\mathrm{G} \alpha_{\mathrm{qG} 66 \mathrm{Di} 5}$ chimeric protein, the compound LP1 was able to stimulate calcium mobilization in a concentration-dependent manner, with a $\mathrm{pEC}_{50}$ of 5.95 and low maximal effect (concentration response curve was not completed) resulting in a partial DOR agonist. The LP1 functional profile at DOR, previously in vitro detected $[14,16]$ by adenylyl cyclase, and the $\left[{ }^{35} \mathrm{~S}\right] \mathrm{GTP} \gamma \mathrm{S}$ binding assays was controversial. Indeed, LP1 dose-dependently inhibited the cAMP accumulation, however, it was approximately 85-fold less potent than DPDPE. These results suggested that LP1 was a weak DOR agonist [14]. Contrarily, low concentrations (10 nM) of LP1 resulted in $30 \%$ inhibition of $\left.{ }^{35} \mathrm{~S}\right] \mathrm{GTP} \gamma \mathrm{S}$ binding [16], suggesting that LP1 at low concentrations acts as an inverse agonist, and inhibits the constitutive coupling that occurs between DOR and G proteins. Similar findings with DOR spontaneous activity and effects of DOR antagonists have been previously 
described [25]. This effect was reversed at higher LP1 concentrations [16]. These [ $\left.{ }^{35} \mathrm{~S}\right] \mathrm{GTP} \gamma \mathrm{S}$ binding results reveal the role of LP1 as a DOR antagonist ligand. Based on the fact that LP1 displays a weak effect on adenyl cyclase activity induced in DOR-expressing cells, we suggested that LP1 is a potent DOR antagonist displaying inverse agonist activity. The DOR antagonist profile of LP1 was also detected in vivo by rat tail flick test. In cells expressing the $\mathrm{G} \alpha_{\mathrm{qG} 66 \mathrm{Di5}}$ chimeric protein, but not DOR, LP1 was found completely inactive up to $10 \mu \mathrm{M}$ (data not shown). Compound 10 was able to stimulate calcium mobilization, but only at the higher concentration tested $(10 \mu \mathrm{M})$. The remaining LP1 derivatives 11-16 were not able to stimulate calcium mobilization in $\mathrm{CHO}^{\mathrm{DOR}}$ cells stably expressing the $\mathrm{G} \alpha_{\mathrm{qG} 66 \mathrm{Di5}}$ protein. In antagonist type experiments, derivatives 11-12 were able to inhibit the stimulatory effects induced by DPDPE, however, the inhibition response curves to these compounds were incomplete. Compounds 13-16 were not able to inhibit the stimulatory effects induced by DPDPE.

In $\mathrm{CHO}^{\mathrm{KOR}}$ cells stably expressing the $\mathrm{G} \alpha_{\mathrm{qi} 5}$ chimeric protein, LP1 and most of its derivatives at higher concentration, up to $10 \mu \mathrm{M}$, did not stimulate calcium release (data not shown). Compound 15 was able to stimulate calcium mobilization in a concentration-dependent manner with a $\mathrm{pEC}_{50}$ of 6.59 , behaving as a low potency and low efficacy $(\alpha=0.32 \pm 0.016)$ partial agonist of KOR. In antagonist type experiments, compounds $\mathbf{1 1}, \mathbf{1 2}$, and $\mathbf{1 6}$ were able to inhibit the stimulatory effects induced by dynorphin $\mathrm{A}$; however, the inhibition response curves to these compounds were incomplete.

In this series, only compound $\mathbf{1 0}$ shares a functional profile with LP1, although it was less active, and it binds MOR and DOR with a $K_{i}$ in the micromolar range. $p$-Methyl- (11) and $p$-cyano- (12) derivatives display comparable functional profile, resulting in MOR partial agonists and DOR/KOR antagonists. Their MOR potencies were higher than compound 10, but lower than LP1. These results enabled us to recognize how the presence of bulkier substituents and their electronic effect in the $\mathrm{N}$-phenylpropanamido chain could be a stringent feature for opioid receptors efficacy profile. The steric hindrance of $\mathrm{N}$-substituents in derivatives 13-16 affects the shift from MOR agonism to antagonism. Moreover, in conformationally restrained compounds 14 and 15, the restriction in the degrees of freedom due to cyclization led to a loss of MOR agonist activity in favor to an antagonist profile. In a previous investigation [18], we already reported that increased ring sizes other than aromatic/heteroaromatic ring orientation of the $N$-substituents with respect to the (-)-cis-N-Normetazocine scaffold modulated affinity, selectivity, and activity towards MOR. The switching of the functional profile from agonism to antagonism versus MOR $\left(\mathrm{pK} \mathrm{K}_{\mathrm{B}}=7.90 \pm 0.60\right)$ of the $N$-1-naphthyl derivative (2) was also confirmed in the calcium mobilization assays.

\section{Materials and Methods}

\subsection{Chemistry}

\subsubsection{General Experimental Procedures}

All commercial chemicals were purchased from Sigma-Aldrich (St. Louis, MO, USA) or Merck (Darmstadt, Germany) and were used without further purification. $( \pm)$-cis-N-Normetazocine was obtained from Fabbrica Italiana Sintetici (Milano, Italy). Melting points were determined in open capillary tubes with a Büchi 530 apparatus (Büchi, Flawil, Switzerland) and are uncorrected. Analytical TLC was performed on silica gel 60 F254 aluminum sheets (Merck, Kenilworth, NJ, USA) with fluorescent indicator. Components were visualized by UV light $(\lambda=254 \mathrm{~nm})$ and iodine vapors. Flash column chromatography was carried out on Merck silica gel 60 (230-400 mesh). Optical rotations were determined in $\mathrm{MeOH}$ solution with a Perkin-Elmer 241 polarimeter (Llantrisant, UK). Infrared spectra were recorded on a 1600 FT-IR Perkin-Elmer instrument (PerkinElmer, Milano, Italy). ${ }^{1} \mathrm{H}$ and ${ }^{13} \mathrm{C}$ NMR spectra were routinely recorded on a Varian Inova-500 spectrometer in $\mathrm{CDCl}_{3}$ or DMSO solution (Varian, Palo Alto, CA, USA); chemical shifts $\delta$ are expressed in ppm with reference to tetramethylsilane as an internal standard. GCMS analysis was recorded using a Shimadzu QP500 EI 171 (70 eV) (Shimadzu Scientific Instruments, Columbia, MD, USA). Elemental analyses (C, H, N) 
were performed on a Carlo Erba 1106 analyzer (Milan, Italy) and the results were within $\pm 0.4 \%$ of the theoretical values. All reported compounds had a purity of at least $95 \%$.

\subsubsection{General Procedure for the Preparation of 3-Bromo Propanamide Derivatives (3-9)}

A solution of the appropriate amine (1 equiv) and 4-(dimethylamino)pyridine (DMAP) (0.47 equiv) in dry THF $(10 \mathrm{~mL})$ was added dropwise to a solution of 3-bromopropionyl chloride (1.5 equiv) in THF $(10 \mathrm{~mL})$ cooled to $0{ }^{\circ} \mathrm{C}$. The reaction mixture was kept under vigorous stirring at room temperature (rt) for $1 \mathrm{~h}$, and was then quenched with $\mathrm{H}_{2} \mathrm{O}$ and extracted with $\mathrm{CHCl}_{3}$. The organic phase was washed with a saturated aqueous solution of $\mathrm{NaHCO}_{3}$ and brine, and dried over anhydrous $\mathrm{Na}_{2} \mathrm{SO}_{4}$. After the solvent was removed in vacuo, the crude product was purified by flash chromatography (cyclohexane/ethyl acetate, 80:20 $\mathrm{v} / \mathrm{v}$ ) to give compounds 3-9.

3-Bromo-N-(4-fluorophenyl)propanamide (3). White solid (76\%); mp: $146.5-147.5{ }^{\circ} \mathrm{C}$; IR (KBr) vmax $1665 \mathrm{~cm}^{-1}$; ${ }^{1} \mathrm{H}$ NMR (DMSO, $\left.500 \mathrm{MHz}\right): \delta 10.08\left(1 \mathrm{H}\right.$, s, exchangeable in $\left.\mathrm{D}_{2} \mathrm{O}\right), 7.62-7.58(2 \mathrm{H}, \mathrm{m})$, 7.15-7.10 (2H, m), $3.71(2 \mathrm{H}, \mathrm{t}, J=6.5 \mathrm{~Hz}), 2.92(2 \mathrm{H}, \mathrm{t}, J=6.5 \mathrm{~Hz}) ;{ }^{13} \mathrm{C}$ NMR (DMSO, $\left.125 \mathrm{MHz}\right) \delta 168.01$, $158.91(J=238.25 \mathrm{~Hz}), 135.32,120.83(J=7.75 \mathrm{~Hz}), 115.34(J=22.37 \mathrm{~Hz}), 39.29,29.11$; MS (EI) $\mathrm{m} / z(\%)$ $244.9[\mathrm{M}+\mathrm{H}]^{+}, 246.9[\mathrm{M}+\mathrm{H}]^{+}$.

3-bromo-N-(4-methylphenyl)propanamide (4). White solid (75\%); mp: 140.0-140.6 ${ }^{\circ} \mathrm{C}$; IR (KBr) vmax $1664 \mathrm{~cm}^{-1} ;{ }^{1} \mathrm{H}$ NMR (DMSO, $\left.500 \mathrm{MHz}\right) \delta 9.89\left(1 \mathrm{H}\right.$, s, exchangeable in $\left.\mathrm{D}_{2} \mathrm{O}\right), 7.40(2 \mathrm{H}, \mathrm{d}, J=8.4 \mathrm{~Hz})$, $7.01(2 \mathrm{H}, \mathrm{d}, J=8.4 \mathrm{~Hz}), 3.63(2 \mathrm{H}, \mathrm{t}, J=6.2 \mathrm{~Hz}), 2.83(2 \mathrm{H}, \mathrm{t}, J=6.2 \mathrm{~Hz}), 2.15(3 \mathrm{H}, \mathrm{s}) ;{ }^{13} \mathrm{C}$ NMR (DMSO, $125 \mathrm{MHz}) \delta 173.24,141.85,137.53,134.36,124.36,44.70,34.69,25.80$; MS (EI) $m / z(\%) 241.0[\mathrm{M}+\mathrm{H}]^{+}$, $243.0[\mathrm{M}+\mathrm{H}]^{+}$.

3-Bromo-N-(4-cyanophenyl)propanamide (5). White solid (85\%); mp: $194.5-195.6{ }^{\circ} \mathrm{C}$; IR (KBr) vmax 2222, $1669 \mathrm{~cm}^{-1} ;{ }^{1} \mathrm{H}$ NMR (DMSO, $\left.500 \mathrm{MHz}\right) \delta 10.47\left(1 \mathrm{H}\right.$, s, exchangeable in $\left.\mathrm{D}_{2} \mathrm{O}\right), 7.78-7.75(4 \mathrm{H}, \mathrm{m}), 3.72$ $(2 \mathrm{H}, \mathrm{t}, J=6.5 \mathrm{~Hz}), 2.99(2 \mathrm{H}, \mathrm{t}, J=6.5 \mathrm{~Hz}) ;{ }^{13} \mathrm{C} \mathrm{NMR}(\mathrm{DMSO}, 125 \mathrm{MHz}) \delta 169.05,143.03,133.27,119.08$, 118.97, 105.06, 39.67, 28.68; MS (EI) $m / z(\%) 251.9[\mathrm{M}+\mathrm{H}]^{+}, 253.9[\mathrm{M}+\mathrm{H}]^{+}$.

3-Bromo-N-(4-methoxyphenyl)propanamide (6). Yellow solid (70\%); mp: 107.5-108.9 ${ }^{\circ} \mathrm{C}$; IR (KBr) vmax $1650 \mathrm{~cm}^{-1} ;{ }^{1} \mathrm{H}$ NMR (DMSO, $\left.500 \mathrm{MHz}\right) \delta 9.88\left(1 \mathrm{H}, \mathrm{s}\right.$, exchangeable in $\left.\mathrm{D}_{2} \mathrm{O}\right), 7.49(2 \mathrm{H}, \mathrm{d}, J=9 \mathrm{~Hz})$, $6.86(2 \mathrm{H}, \mathrm{d}, J=9 \mathrm{~Hz}), 3.71(2 \mathrm{H}, \mathrm{t}, J=6.5 \mathrm{~Hz}), 3.70(3 \mathrm{H}, \mathrm{s}), 2.89(2 \mathrm{H}, \mathrm{t}, J=6.5 \mathrm{~Hz}) ;{ }^{13} \mathrm{C}$ NMR (DMSO, $125 \mathrm{MHz}) \delta 167.54,155.19,132.11,120.60,113.81,55.11,39.24,29.31$; MS (EI) $m / z(\%) 257.0[\mathrm{M}+\mathrm{H}]^{+}$, $259.0[\mathrm{M}+\mathrm{H}]^{+}$.

3-Bromo-1-(2,3-dihydro-1H-indol-1-yl)propan-1-one (7). White solid (79\%); mp: 91.0-91.8 ${ }^{\circ} \mathrm{C}$; $\mathrm{IR}(\mathrm{KBr})$ $\operatorname{vmax} 1653 \mathrm{~cm}^{-1},{ }^{1} \mathrm{H}$ NMR $\left(\mathrm{CDCl}_{3}, 500 \mathrm{MHz}\right) \delta 8.22(1 \mathrm{H}, \mathrm{d}), 7.21-7.18(2 \mathrm{H}, \mathrm{m}), 7.04-7.01(1 \mathrm{H}, \mathrm{t}), 4.06$ $(2 \mathrm{H}, \mathrm{t}, J=6.8 \mathrm{~Hz}), 3.73(2 \mathrm{H}, \mathrm{t}, J=6.6 \mathrm{~Hz}), 3.21(2 \mathrm{H}, \mathrm{t}, J=6.8 \mathrm{~Hz}), 3.02(2 \mathrm{H}, \mathrm{t}, J=6.6 \mathrm{~Hz}) ;{ }^{13} \mathrm{C}$ NMR $\left(\mathrm{CDCl}_{3}, 125 \mathrm{MHz}\right) \delta 168.74,142.41,131.43,126.91,124.50,123.01,116.83,48.53,38.60,31.00,27.88$; MS (EI) $m / z(\%) 253.0[\mathrm{M}+\mathrm{H}]^{+}, 255.0[\mathrm{M}+\mathrm{H}]^{+}$.

3-Bromo-1-(3,4-dihydroquinolin-1(2H)-yl)propan-1-one (8). White solid (70\%); mp: 67.5-68.5 ${ }^{\circ} \mathrm{C}$; IR ( $\mathrm{KBr}$,) vmax $1652 \mathrm{~cm}^{-1} ;{ }^{1} \mathrm{H}$ NMR $\left(\mathrm{CDCl}_{3}, 500 \mathrm{MHz}\right) \delta 7.21-7.10(4 \mathrm{H}, \mathrm{m}), 3.81(2 \mathrm{H}, \mathrm{t}, J=6.6 \mathrm{~Hz}), 3.67(2 \mathrm{H}, \mathrm{t}$, $J=6.8 \mathrm{~Hz}), 3.08(2 \mathrm{H}, \mathrm{t}, J=6.8 \mathrm{~Hz}), 2.72(2 \mathrm{H}, \mathrm{t}, J=6.6 \mathrm{~Hz}), 1.97(2 \mathrm{H}, \mathrm{q}, J=6.6 \mathrm{~Hz}) ;{ }^{13} \mathrm{C} \mathrm{NMR}\left(\mathrm{CDCl}_{3}\right.$, $125 \mathrm{MHz}) \delta 169.84,138.68,128.78,127.67,126,41,125.86,124.74,43.35,37.70,28.27,26.88,24.22$; MS (EI) $m / z(\%) 267.0[\mathrm{M}+\mathrm{H}]^{+}, 269.0[\mathrm{M}+\mathrm{H}]^{+}$.

3-Bromo-N,N-diphenylpropanamide (9). White solid (72\%); mp: 95.9-96.4 ${ }^{\circ} \mathrm{C}$; IR (KBr,) vmax $1673 \mathrm{~cm}^{-1}$; ${ }^{1} \mathrm{H} \mathrm{NMR}\left(\mathrm{CDCl}_{3}, 500 \mathrm{MHz}\right) \delta 7.28-7.21(10 \mathrm{H}, \mathrm{m}), 3.65(2 \mathrm{H}, \mathrm{t}, J=6.6 \mathrm{~Hz}), 2.83(2 \mathrm{H}, \mathrm{t}, J=6.6 \mathrm{~Hz}) ;{ }^{13} \mathrm{C}$ NMR $\left(\mathrm{CDCl}_{3}, 125 \mathrm{MHz}\right) \delta 169.15,142.51,128.86,126.13,125.00,38.12,27.57$; MS (EI) $\mathrm{m} / z$ (\%) 303.0 $[\mathrm{M}+\mathrm{H}]^{+}, 305.0[\mathrm{M}+\mathrm{H}]^{+}$. 
3.1.3. General Procedure for the Synthesis of N-Substituted (-)-Cis-N-Normetazocine Derivatives (10-16)

A mixture of (-)-cis-(1R,5R,9R)-N-Normetazocine (1 equiv), the appropriate 3-bromoamide derivatives (3-9, 1.5 equiv), $\mathrm{NaHCO}_{3}$ (1.5 equiv), and a catalytic amount of KI was stirred in DMF at $50{ }^{\circ} \mathrm{C}$ for $12 \mathrm{~h}$. After cooling, the reaction mixture was concentrated under vacuum to remove DMF. The resulting residue was purified by flash chromatography using a silica gel column with a $\mathrm{CHCl}_{3} / \mathrm{CH}_{3} \mathrm{OH}(95: 5, v / v)$ solvent system. Target compounds 10-16 were recrystallized from absolute ethanol to give white solids.

N-(4-Fluorophenyl)-3-[(2R,6R,11R)-8-hydroxy-6,11-dimethyl-1,4,5,6-tetrahydro-2,6-methano-3-benzazocin3(2H)-yl]propanamide (10). White solid (50\%); mp: $199.7-201.3{ }^{\circ} \mathrm{C} ;[\alpha]_{D}^{25}=-56^{\circ}$ (c $\left.1.0, \mathrm{MeOH}\right) ;{ }^{1} \mathrm{H}$ NMR (DMSO, $500 \mathrm{MHz}) \delta 10.23(1 \mathrm{H}, \mathrm{s}), 7.62(2 \mathrm{H}, \mathrm{d}, J=8.8 \mathrm{~Hz}), 7.15(2 \mathrm{H}, \mathrm{d}, J=8.8 \mathrm{~Hz}), 6.89(1 \mathrm{H}, \mathrm{d}$, $J=8.4 \mathrm{~Hz}), 6.59(1 \mathrm{H}, \mathrm{d}, J=2.5 \mathrm{~Hz}), 6.53(1 \mathrm{H}, \mathrm{dd}, J=8.4 \mathrm{~Hz}, J=2.5 \mathrm{~Hz}), 2.91-2.71(3 \mathrm{H}, \mathrm{m}), 2.62-2.44$ $(6 \mathrm{H}, \mathrm{m}), 1.99-1.95(1 \mathrm{H}, \mathrm{m}), 1.72-1.71(1 \mathrm{H}, \mathrm{m}), 1.27(3 \mathrm{H}, \mathrm{s}), 1.20(1 \mathrm{H}, \mathrm{m}), 0.78(3 \mathrm{H}, \mathrm{d}, J=5 \mathrm{~Hz}) ;{ }^{13} \mathrm{C}$ NMR (DMSO, $125 \mathrm{MHz}) \delta 170.18,158.73(J=240.37 \mathrm{~Hz}), 155.43,142.28,135.63,127.76,126.34,120.70$ $(J=7.75 \mathrm{~Hz}), 115.30(J=21.87 \mathrm{~Hz}), 112.87,111.80,56.88,50.37,44.80,41.84,41.26,35.88,34.04,25.24$, 23.20, 13.89; MS (EI) $m / z(\%) 383.2[\mathrm{M}+\mathrm{H}]^{+}, 229.9\left[\mathrm{M}-\mathrm{CH}_{2} \mathrm{CONHC}_{6} \mathrm{H}_{4} \mathrm{~F}\right] ;$ anal. C, 72.11; H, 7.19; N, $7.22 \%$, calcd for $\mathrm{C}_{23} \mathrm{H}_{27} \mathrm{FN}_{2} \mathrm{O}_{2}(382,471) \mathrm{C}, 72.23 ; \mathrm{H}, 7.12 ; \mathrm{N}, 7.32 \%$.

3-[(2R,6R,11R)-8-Hydroxy-6,11-dimethyl-1,4,5,6-tetrahydro-2,6-methano-3-benzazocin-3(2H)-yl]-N-(4methylphenyl)propanamide (11). White solid (61\%); mp: $180.5-181.8{ }^{\circ} \mathrm{C} ;[\alpha]_{D}^{25}=-51^{\circ}(\mathrm{c} 1.0, \mathrm{MeOH}) ;{ }^{1} \mathrm{H}$ NMR (DMSO, $500 \mathrm{MHz}) \delta 10.05(1 \mathrm{H}, \mathrm{s}), 7.44(2 \mathrm{H}, \mathrm{d}, J=8.0 \mathrm{~Hz}), 7.08(2 \mathrm{H}, \mathrm{d}, J=8.0 \mathrm{~Hz}), 6.86(1 \mathrm{H}, \mathrm{d}$, $J=8.5 \mathrm{~Hz}), 6.60(1 \mathrm{H}, \mathrm{d}, J=2.5 \mathrm{~Hz}), 6.50(1 \mathrm{H}, \mathrm{dd}, J=8.5 \mathrm{~Hz}, J=2.5 \mathrm{~Hz}), 2.90(1 \mathrm{H}, \mathrm{m}), 2.87-2.82(2 \mathrm{H}, \mathrm{m})$, 2.67-2.66 (2H, m), 2.58-2.49 (2H, m), 2.45-2.35 (2H, m), $2.23(3 \mathrm{H}, \mathrm{s}), 2.00-1.90(1 \mathrm{H}, \mathrm{m}), 1.692-1.632$ $(1 \mathrm{H}, \mathrm{m}), 1.25(3 \mathrm{H}, \mathrm{s}), 1.21(1 \mathrm{H}, \mathrm{m}), 0.75(3 \mathrm{H}, \mathrm{d}, J=5 \mathrm{~Hz}) ;{ }^{13} \mathrm{C}$ NMR (DMSO, $\left.125 \mathrm{MHz}\right) \delta 170.00,155.44$, 142.24, 136.73, 131.80, 129.04, 127.77, 126.30, 118.99, 112.88, 111.80, 56.88, 50.39, 44.80, 41.81, 41.24, 35.87, 34.95, 25.23, 23.19, 20.38, 13.87; MS (EI) $m / z$ (\%) $379.3[\mathrm{M}+\mathrm{H}]^{+}, 230.2\left[\mathrm{M}-\mathrm{CH}_{2} \mathrm{CONHC}_{7} \mathrm{H}_{7}\right]$; anal. C, 76.02; $\mathrm{H}, 8.03 ; \mathrm{N}, 7.22 \%$, calcd for $\mathrm{C}_{24} \mathrm{H}_{30} \mathrm{~N}_{2} \mathrm{O}_{2}(378,507) \mathrm{C}, 76.16 ; \mathrm{H}, 7.99 ; \mathrm{N}, 7.40 \%$.

N-(4-Cyanophenyl)-3-[(2R,6R,11R)-8-hydroxy-6,11-dimethyl-1,4,5,6-tetrahydro-2,6-methano-3-benzazocin-3 (2H)-yllpropanamide (12). White solid (67\%); mp: $215.1-216{ }^{\circ} \mathrm{C} ;[\alpha]_{D}^{25}=-54.5^{\circ}$ (c 1.0, MeOH); ${ }^{1} \mathrm{H} \mathrm{NMR}$ (DMSO, $500 \mathrm{MHz}) \delta 10.56(1 \mathrm{H}, \mathrm{s}), 7.76(4 \mathrm{H}, \mathrm{m}), 6.87(1 \mathrm{H}, \mathrm{d}, J=8.5 \mathrm{~Hz}), 6.61(1 \mathrm{H}, \mathrm{d}, J=2.5 \mathrm{~Hz}), 6.51$ $(1 \mathrm{H}, \mathrm{dd}, J=8.5 \mathrm{~Hz}, J=2.5 \mathrm{~Hz}), 2.89-2.79(3 \mathrm{H}, \mathrm{m}), 2.73-2.67(2 \mathrm{H}, \mathrm{m}), 2.59-2.46(4 \mathrm{H}, \mathrm{m}), 2.02-1.97(1 \mathrm{H}$, $\mathrm{m}), 1.74-1.63(1 \mathrm{H}, \mathrm{m}), 1.25(3 \mathrm{H}, \mathrm{s}), 1.22(1 \mathrm{H}, \mathrm{m}), 0.75(3 \mathrm{H}, \mathrm{d}, J=5 \mathrm{~Hz}) ;{ }^{13} \mathrm{C}$ NMR $(\mathrm{DMSO}, 125 \mathrm{MHz})$ $\delta 171.17,155.44,142.79,142.24,133.25,127.76,126.29,119.04,118.96,112.87,111.79,104.67,56.93$, 50.16, 44.81, 41.78, 41.18, 35.85, 35.27, 25.21, 23.25, 13.87; MS (EI) $m / z$ (\%) $390.3[\mathrm{M}+\mathrm{H}]^{+}, 230.2$ [M- $\left.\mathrm{CH}_{2} \mathrm{CONHC}_{7} \mathrm{H}_{4} \mathrm{~N}\right]$; anal. C, 73.89; $\mathrm{H}, 7.05 ; \mathrm{N}, 10.52 \%$, calcd for $\mathrm{C}_{24} \mathrm{H}_{27} \mathrm{~N}_{3} \mathrm{O}_{2}(389,490) \mathrm{C}, 74.01 ; \mathrm{H}$, $6.99 ; \mathrm{N}, 10.79 \%$.

3-[(2R,6R,11R)-8-Hydroxy-6,11-dimethyl-1,4,5,6-tetrahydro-2,6-methano-3-benzazocin-3(2H)-yl]-N-(4methoxyphenyl)propanamide (13). White solid (58\%); mp: $172.9-173.5^{\circ} \mathrm{C} ;[\alpha]_{D}^{25}=-53^{\circ}(\mathrm{c} 1.0, \mathrm{MeOH}) ;{ }^{1} \mathrm{H}$ NMR (DMSO, $500 \mathrm{MHz}) \delta 10.01(\mathrm{~s}, 1 \mathrm{H}), 7.47(2 \mathrm{H}, \mathrm{d}, J=9.0 \mathrm{~Hz}), 6.87(3 \mathrm{H}, \mathrm{dd}, J=9.0 \mathrm{~Hz}, J=8.4 \mathrm{~Hz})$, $6.61(1 \mathrm{H}, \mathrm{d}, J=2.5 \mathrm{~Hz}), 6.52(1 \mathrm{H}, \mathrm{dd}, J=8.5 \mathrm{~Hz}, J=2.5 \mathrm{~Hz}), 3.71(3 \mathrm{H}, \mathrm{s}), 2.90-2.89(1 \mathrm{H}, \mathrm{m}), 2.83-2.80$ $(2 \mathrm{H}, \mathrm{m}), 2.73-2.67(2 \mathrm{H}, \mathrm{m}), 2.59-2.54(2 \mathrm{H}, \mathrm{m}), 2.41-2.40(2 \mathrm{H}, \mathrm{m}), 2.01-1.97(1 \mathrm{H}, \mathrm{m}), 1.75-1.65(1 \mathrm{H}, \mathrm{m})$, $1.26(3 \mathrm{H}, \mathrm{s}), 1.25-1.23(1 \mathrm{H}, \mathrm{m}), 0.76(3 \mathrm{H}, \mathrm{d}, J=5 \mathrm{~Hz}) ;{ }^{13} \mathrm{C}$ NMR (DMSO, $\left.125 \mathrm{MHz}\right) \delta 169.72,155.43$, 154.98, 142.26, 132.42, 127.76, 126.32, 120.48, 113.81, 112.87, 111.79, 56.86, 55.10, 50.43, 44.78, 41.80, 41.25, 35.87, 34.87, 25.22, 23.15, 13.87; MS (EI) $\mathrm{m} / z$ (\%) $395.3[\mathrm{M}+\mathrm{H}]^{+}, 230.3\left[\mathrm{M}-\mathrm{CH}_{2} \mathrm{CONHC}_{7} \mathrm{H}_{7} \mathrm{O}\right]$; anal. C, 73.00; $\mathrm{H}, 7.68 ; \mathrm{N}, 7.08 \%$, calcd for $\mathrm{C}_{24} \mathrm{H}_{27} \mathrm{~N}_{3} \mathrm{O}_{2}(394,506) \mathrm{C}, 73.07 ; \mathrm{H}, 7.66 ; \mathrm{N}, 7.10 \%$.

1-(2,3-Dihydro-1H-indol-1-yl)-3-[(2R,6R,11R)-8-hydroxy-6,11-dimethyl-1,4,5,6-tetrahydro-2,6-methano-3benzazocin-3(2H)-yl]propan-1-one (14). White solid (56\%); mp: $169{ }^{\circ} \mathrm{C} \mathrm{dec;}[\alpha]_{D}^{25}=-38.5^{\circ}$ (c 1.0, $\left.\mathrm{MeOH}\right)$; ${ }^{1} \mathrm{H}$ NMR (DMSO, $\left.500 \mathrm{MHz}\right) \delta 8.07(1 \mathrm{H}, \mathrm{d}), 7.22(1 \mathrm{H}, \mathrm{d}, J=7.4 \mathrm{~Hz}), 7.14(1 \mathrm{H}, \mathrm{t}, J=7.8 \mathrm{~Hz}), 6.98(1 \mathrm{H}$, $\mathrm{t}, J=7.4 \mathrm{~Hz}), 6.89(1 \mathrm{H}, \mathrm{d}, J=8.4 \mathrm{~Hz}), 6.61(1 \mathrm{H}, \mathrm{d}, J=2.2 \mathrm{~Hz}), 6.52(1 \mathrm{H}, \mathrm{dd}, J=8.4 \mathrm{~Hz}, J=2.2 \mathrm{~Hz})$, 
$4.11(2 \mathrm{H}, \mathrm{t}, J=8.5 \mathrm{~Hz}), 3.13(2 \mathrm{H}, \mathrm{t}, J=8.5 \mathrm{~Hz}), 2.89-2.81(3 \mathrm{H}, \mathrm{m}), 2.68-2.64(2 \mathrm{H}, \mathrm{m}), 2.55-2.50(4 \mathrm{H}, \mathrm{m})$, 2.00-1.98 $(1 \mathrm{H}, \mathrm{m}), 1.74-1.64(1 \mathrm{H}, \mathrm{m}), 1.26(3 \mathrm{H}, \mathrm{s}), 1.20(1 \mathrm{H}, \mathrm{m}), 0.76(3 \mathrm{H}, \mathrm{d}, J=5 \mathrm{~Hz}) ;{ }^{13} \mathrm{C}$ NMR (DMSO, $125 \mathrm{MHz}) \delta 172.30,153.70,147.02,142.50,134.13,128.17,127.52,126.76,124.68,123.64,116.40,112.83$, 111.76, 57.20, 47.07, 46.71, 46.46, 40.26, 38.50, 35.75, 33.67, 28.21, 25.46, 22.59, 14.52; MS (EI) $\mathrm{m} / z$ (\%) $391.5[\mathrm{M}+\mathrm{H}]^{+}, 230.1\left[\mathrm{M}-\mathrm{CH}_{2} \mathrm{CONC}_{8} \mathrm{H}_{8}\right]$; anal. C, 76.68; H, 7.90; N, 7.05\%, calcd for $\mathrm{C}_{25} \mathrm{H}_{30} \mathrm{~N}_{2} \mathrm{O}_{2}$ $(390,518)$ C, $76.89 ; \mathrm{H}, 7.74 ; \mathrm{N}, 7.17 \%$.

1-(3,4-Dihydroquinolin-1(2H)-yl)-3-[(2R,6R,11R)-8-hydroxy-6,11-dimethyl-1,4,5,6-tetrahydro-2,6-methano-3benzazocin-3(2H)-yll-propan-1-one (15). White solid (42\%); mp: $92.2^{\circ} \mathrm{C} \mathrm{dec} ;[\alpha]_{D}^{25}=-37^{\circ}(\mathrm{c} 1.0, \mathrm{MeOH})$; ${ }^{1} \mathrm{H}$ NMR (DMSO, $\left.500 \mathrm{MHz}\right) \delta 7.37(1 \mathrm{H}, \mathrm{d}, J=8.0 \mathrm{~Hz}), 7.19-7.07(3 \mathrm{H}, \mathrm{m}), 6.82(1 \mathrm{H}, \mathrm{d}, J=8.2 \mathrm{~Hz}), 6.56$ $(1 \mathrm{H}, \mathrm{d}, J=2.4 \mathrm{~Hz}), 6.47(1 \mathrm{H}, \mathrm{dd}, J=8.2 \mathrm{~Hz}, J=2.2 \mathrm{~Hz}), 3.66(2 \mathrm{H}, \mathrm{t}, J=6.4 \mathrm{~Hz}), 2.75-2.67(5 \mathrm{H}, \mathrm{m})$, 2.63-2.46 (4H, m), 2.30-2.26 (2H, m), 1.91-1.84 (2H, m), 1.65-1.56 (2H, m), $1.21(3 \mathrm{H}, \mathrm{s}), 1.11(1 \mathrm{H}, \mathrm{m})$, $0.69(3 \mathrm{H}, \mathrm{d}, J=5 \mathrm{~Hz}) ;{ }^{13} \mathrm{C}$ NMR (DMSO, $\left.125 \mathrm{MHz}\right) \delta 171.25,155.39,142.27,139.10,138.91,128.37$, $127.72,126.34,126.12,125.68,124.64,112.83,111.76,57.20,51.00,47.01,45.09,41.76,41.14,35.75,35.07$, 32.67, 26.21, 25.25, 23.68, 23.19, 13.82; MS (EI) $m / z(\%) 405.1[\mathrm{M}+\mathrm{H}]^{+}, 230.1\left[\mathrm{M}-\mathrm{CH}_{2} \mathrm{CONC}_{9} \mathrm{H}_{10}\right]$; anal. C, 77.03; $\mathrm{H}, 8.05 ; \mathrm{N}, 6.78 \%$, calcd for $\mathrm{C}_{26} \mathrm{H}_{32} \mathrm{~N}_{2} \mathrm{O}_{2}(404,544) \mathrm{C}, 77.19 ; \mathrm{H}, 7.97 ; \mathrm{N}, 6.92 \%$.

3-[(2R,6R,11R)-8-Hydroxy-6,11-dimethyl-1,4,5,6-tetrahydro-2,6-methano-3-benzazocin-3(2H)-yl]-N,Ndiphenylpropanamide (16). White solid (70\%); mp: $173.5^{\circ} \mathrm{C} \mathrm{dec;}[\alpha]_{D}^{25}=-32^{\circ}$ (c 1.0, MeOH); ${ }^{1} \mathrm{H} \mathrm{NMR}$ (DMSO, $500 \mathrm{MHz}) \delta 7.40-7.32(10 \mathrm{H}, \mathrm{m}), 6.84(1 \mathrm{H}, \mathrm{d}, J=8.5 \mathrm{~Hz}), 6.58(1 \mathrm{H}, \mathrm{d}, J=2.5 \mathrm{~Hz}), 6.49(1 \mathrm{H}$, $\mathrm{dd}, J=8.4 \mathrm{~Hz}, J=2.5 \mathrm{~Hz}), 2.80-2.73(1 \mathrm{H}, \mathrm{m}), 2.70-2.67(2 \mathrm{H}, \mathrm{m}), 2.60-2.56(1 \mathrm{H}, \mathrm{m}), 2.49-2.45(1 \mathrm{H}, \mathrm{m})$, 2.33-2.23 (2H, m), 1.92-1.88 (2H, m), 1.71-1.70 (1H, m), 1.65-1.59 (1H, m), $1.25(3 \mathrm{H}, \mathrm{s}), 1.15(1 \mathrm{H}, \mathrm{m})$, $0.73(3 \mathrm{H}, \mathrm{d}, J=5 \mathrm{~Hz}) ;{ }^{13} \mathrm{C}$ NMR (DMSO, $\left.125 \mathrm{MHz}\right) \delta 171.24,155.38,143.04,142.31,128.46,127.71$, $126.39,126.15,125.00,112.82,111.76,57.27,50.79,45.04,41.76,41.12,35.81,33.42,25.25,23.36,13.87$; MS (EI) $\mathrm{m} / \mathrm{z}(\%) 441.4[\mathrm{M}+\mathrm{H}]^{+}, 230.1\left[\mathrm{M}-\mathrm{CH}_{2} \mathrm{CONC}_{12} \mathrm{H}_{10}\right]$; anal. C, 79.32; $\mathrm{H}, 7.54 ; \mathrm{N}, 6.44 \%$, calcd for $\mathrm{C}_{29} \mathrm{H}_{32} \mathrm{~N}_{2} \mathrm{O}_{2}(440,576) \mathrm{C}, 79.06 ; \mathrm{H}, 7.32 ; \mathrm{N}, 6.36 \%$.

\subsection{Biological Assays}

\subsubsection{Drugs and Reagents}

$\left[{ }^{3} \mathrm{H}\right]$-Diprenorphine $\left(\left[{ }^{3} \mathrm{H}\right]-\mathrm{DPN}\right)\left(42.30 \mathrm{C}_{\mathrm{i}} / \mathrm{mmol}\right)$ was purchased from Perkin Elmer Life Sciences (NET11212, 250 $\mathrm{Ci}$, Boston, MA, USA) and naloxone hydrochloride was purchased from Sigma-Aldrich (St. Louis, MO, USA). DPDPE ([D-Pen ${ }^{2}$, D-Pen $\left.{ }^{5}\right]$ enkephalin) and dynorphin A were purchased from Neosystem. Dermorphin was prepared and purified in house as previously described [26]. Stock solutions $(10 \mathrm{mM})$ of peptides were made in distilled water, while LP1 and its derivatives in DMSO and kept at $-20^{\circ} \mathrm{C}$ until use. The compounds were solubilized in saline at $1 \mu \mathrm{M}$, with the only exception of naloxone, which was at $10 \mu \mathrm{M}$. Successive dilutions of standard ligands were made in saline, whereas LP1 and its analogues were solubilized in HBSS (Hank's balanced salt solution)/HEPES (4-(2-hydroxyethyl)-1-piperazineethanesulfonic acid) (20 mM) buffer (containing $0.005 \%$ bovine serum albumin (BSA) fraction V). Tissue culture media and supplements were from Invitrogen (Carlsbad, CA, USA) and from Cambrex Bioscience (Walkersville, MD, USA).

\subsubsection{Cell Membrane Preparations}

Confluent monolayers of HEK293 (human embryonic kidney 293) cells stably expressing rat-MOR, rat-DOR, or human-KOR were harvested, collected by centrifugation at $1500 \mathrm{rpm}$ for $5 \mathrm{~min}$, and washed once with phosphate-buffered saline (PBS) at pH 7.5. Membranes from cell pellets were carried out as described by Georgoussi and Zioudrou [25] (1993) and Papakonstantinou et al. [20] (2015). Briefly, cell pellets were resuspended in ice-cold membrane buffer (10 mM Tris- $\mathrm{HCl}, \mathrm{pH} 7.5$ and $0.1 \mathrm{mM}$ EDTA), homogenized, and centrifuged at 2,000 g for $3 \mathrm{~min}$ at $4{ }^{\circ} \mathrm{C}$. Supernatants were further centrifuged at $45,000 \mathrm{rpm}$ for $30 \mathrm{~min}$ at $4{ }^{\circ} \mathrm{C}$. The membrane pellet was resuspended in ice-cold membrane buffer 
at a protein concentration of approximately $1 \mathrm{mg} / \mathrm{mL}$ and stored in aliquots at $-70{ }^{\circ} \mathrm{C}$. Protein concentration was determined according to Bradford assay $[27,28]$.

\subsubsection{In Vitro Competition Radioligand Binding Assay}

In the experiments designed to define compound affinity and selectivity for MOR, DOR, and $\mathrm{KOR}$, membranes expressing each of these opioid receptors $(20 \mathrm{mg})$ were incubated at $30{ }^{\circ} \mathrm{C}$ for $45 \mathrm{~min}$ in buffer containing $50 \mathrm{mM}$ Tris- $\mathrm{HCl}, \mathrm{pH} 7.5,100 \mathrm{mM} \mathrm{NaCl}$, and $10 \mathrm{mM} \mathrm{MgCl}_{2}$ as described by Georgoussi et al. [29] (1997). The ability of compounds 10-16 to displace [ $\left.{ }^{3} \mathrm{H}\right]-\mathrm{DPN}$ (3.75 nM) binding to the opioid receptors was assessed as described by Morou And Georgoussi [30] (2005). Non-specific binding was measured in the presence of $10 \mathrm{mM}$ Naloxone. The reaction was stopped by rapid filtration and three washes in ice-cold $50 \mathrm{mM}$ Tris-HCl, pH 7.4, through GF/C filters (Whatman, Maidstone, UK) using an automated cell harvester (Brandel Inc., Gaithersburg, MD, USA). The radioactivity was measured by liquid scintillation counting (Liquid Scintillation Analyzer, Packard).

\subsubsection{Transfection Procedures and Cell Culture}

Chinese hamster ovary $(\mathrm{CHO})$ cells expressing the recombinant human MOR and $\mathrm{KOR}\left(\mathrm{CHO}^{\mathrm{MOR}}\right.$ and $\mathrm{CHO}^{\mathrm{KOR}}$ ) were kindly provided by Dr. Larry Toll (SRI International, Menlo Park, CA, USA), and $\mathrm{CHO}$ cells expressing the recombinant human DOR $\left(\mathrm{CHO}^{\mathrm{DOR}}\right)$ were supplied by Dr. Eva Varga (Department of Medical Pharmacology, The University of Arizona, Tucson, AZ, USA). CHO cells lines permanently coexpressing the opioid receptors and the C-terminally modified $\mathrm{G} \alpha_{\mathrm{qi} 5}$ were prepared by infecting the $\mathrm{CHO}$ lines described above with a recombinant retrovirus expressing the chimeric $\alpha$ subunit and the hygromycin resistance gene. Similarly, $\mathrm{CHO}$ cells lines permanently coexpressing DOR and the C-terminally modified $\mathrm{G} \alpha_{\mathrm{qG} 66 \mathrm{Di} 5}$ were prepared by infecting the CHO lines described above with a recombinant retrovirus expressing the chimeric $\alpha$ subunit and the hygromycin resistance gene. Polyclonal cell lines were generated using the pantropic retroviral expression system form BD-Clontech, as described previously. Stable lines were selected under hygromycin B $(100 \mu \mathrm{g} / \mathrm{mL})$ and geneticin $(600 \mu \mathrm{g} / \mathrm{mL})$ for $2-3$ weeks after the infection.

\subsubsection{Cell Culture and Calcium Mobilization Experiments}

$\mathrm{CHO}$ cells, expressing human opioid receptors and the $\mathrm{G} \alpha_{\mathrm{qi} 5}$ protein, and $\mathrm{CHO}_{\mathrm{DOR}}$, expressing the $\mathrm{G} \alpha_{\mathrm{qG} 66 \mathrm{Di} 5}$ protein, were maintained in culture medium consisting of Dulbecco minimum essential medium (DMEM) and Ham F-12 (1:1) (50/50) supplemented with $10 \%$ fetal calf serum (FCS), L-glutamine (2 mM), geneticin (200 $\mu \mathrm{g} / \mathrm{mL} ; \mathrm{G} 418)$, hygromycin B (100 $\mu \mathrm{g} / \mathrm{mL})$ at $37{ }^{\circ} \mathrm{C}$ in $5 \% \mathrm{CO}_{2}$ humidified air. When confluence was reached (3-4 days), cells were subcultured as required using trypsin/EDTA, and used for experimentation. The different cell lines were seeded at a density of 50,000-40,000 cells/well into black 96-well, clear-bottomed plates. After $24 \mathrm{~h}$ incubation, the cells were loaded with medium supplemented with $2.5 \mathrm{mM}$ probenecid, $3 \mu \mathrm{M}$ of the calcium sensitive fluorescent dye Fluo- 4 AM, and $0.01 \%$ pluronic acid, for $30 \mathrm{~min}$ at $37{ }^{\circ} \mathrm{C}$. Afterwards, the loading solution was aspirated and $100 \mu \mathrm{L} /$ well of assay buffer-HBSS supplemented with 20 mM HEPES, $2.5 \mathrm{mM}$ probenecid and $500 \mu \mathrm{M}$ Brilliant Black (Aldrich, St. Louis, MO, USA)—was added. Serial dilutions of ligands for experimental use were made in HBSS/HEPES (20 mM) buffer (containing $0.005 \%$ BSA fraction V). After placing both plates (cell culture and compound plate) into the FlexStation II (Molecular Device, Union City, San Jose, CA 94587, USA), fluorescence changes were measured at room temperature. Online additions were carried out in a volume of $50 \mu \mathrm{L} /$ well. Antagonists were incubated $15 \mathrm{~min}$ before the addition of the agonist. Maximum change in fluorescence, expressed in percent of baseline fluorescence, was used to determine agonist response.

\subsubsection{Data Analysis}

Analysis of the binding data was performed using the Origin 7.5 software (OriginLab Corporation, Northampton, MA, USA). In calcium mobilization experiments, data were analyzed by non-linear 
curve fitting equation, using GraphPad 5.0 software. For potency values, 95\% confidence limits (CL95\%) were indicated. Ligand efficacy was expressed as intrinsic activity $(\alpha)$, calculated as the ratio between the $\mathrm{E}_{\max }$ of the ligand and that of the respective standards. Calcium mobilization data were expressed as FIU (fluorescence intensity units) in percent, over the baseline. Agonist potencies are given as $\mathrm{pEC}_{50}$ (the negative logarithm to base 10 of the molar concentration of an agonist that produces $50 \%$ of the maximal possible effect, $\left.\mathrm{E}_{\max }\right)$. Concentration response curves to agonists were fitted with the following equation:

$$
\text { Effect }=\text { baseline }+\left(\mathrm{E}_{\max }-\text { baseline }\right) /\left(1+10^{\left(\operatorname{LogEC}_{50}-\mathrm{X}\right) * \text { HillSlope }}\right)
$$

where $\mathrm{X}$ is the agonist concentration.

Antagonist potencies were derived from inhibition experiments and expressed as $\mathrm{pK} \mathrm{B}_{\mathrm{B}}$ calculated from the following equation:

$$
\mathrm{K}_{\mathrm{B}}=\mathrm{IC}_{50} /\left(\left[2+\left([\mathrm{A}] / \mathrm{EC}_{50}\right)^{\mathrm{n}}\right]^{1 / \mathrm{n}}\right)-1
$$

where $\mathrm{IC}_{50}$ is the concentration of antagonist that produces $50 \%$ inhibition of the agonist response, [A] is the concentration of agonist, $\mathrm{EC}_{50}$ is the concentration of agonist producing a $50 \%$ maximal response, and $\mathrm{n}$ is the Hill coefficient of the concentration response curve to the agonist.

\section{Conclusions}

Here, to improve the body of information on (-)-cis- $N$-Normetazocine-based compounds SARs, the synthesis and in vitro characterization of a new series of compounds (10-16) were reported. Collectively, our data corroborated the importance of the phenyl ring in the $N$-propanamido substituent of the (-)-cis-N-Normetazocine scaffold of the reference compound LP1 for MOR and DOR functional profile. Although all synthesized compounds, in comparison to the lead compound LP1, exhibited a worse efficacy profile, they could represent a template in the achievement of a specific functional profile, by modifying $N$-substituent electronic and steric features.

Author Contributions: R.T., C.P. and L.P. designed and performed chemistry and in vitro experiments; P.P. and Z.G. designed and performed radioligand binding assay; G.C., V.C. and E.A. designed and performed calcium mobilization experiments; L.P., C.P., R.T., E.A. and L.M. participated in the analysis and interpretation of data. R.T., C.P. and L.P. wrote the manuscript. All the authors read and approved the final manuscript.

Acknowledgments: This work was supported by University of Catania (PdR 2016-2018) to Lorella Pasquinucci. The authors gratefully acknowledge Fabbrica Italiana Sintetici (Italy) for providing ( \pm )-cis-N-Normetazocine.

Conflicts of Interest: The authors declare no conflict of interest.

\section{References}

1. Janecka, A.; Fichna, J.; Janecki, T. Opioid receptors and their ligands. Curr. Top. Med. Chem. 2004, 4, 1-17. [CrossRef] [PubMed]

2. Turnaturi, R.; Aricò, G.; Ronsisvalle, G.; Parenti, C.; Pasquinucci, L. Multitarget opioid ligands in pain relief: New players in an old game. Eur. J. Med. Chem. 2016, 108, 211-228. [CrossRef] [PubMed]

3. Turnaturi, R.; Aricò, G.; Ronsisvalle, G.; Pasquinucci, L.; Parenti, C. Multitarget Opioid/Non-opioid Ligands: A Potential Approach in Pain Management. Curr. Med. Chem. 2016, 23, 4506-4528. [CrossRef] [PubMed]

4. Turnaturi, R.; Pasquinucci, L.; Parenti, C. From Plant to Bench: Natural Products as Source for Analgesic Drug Development. Front. Nat. Prod. Chem. 2018. submitted for publication.

5. Pathan, H.; Williams, J. Basic opioid pharmacology: An update. Br. J. Pain 2012, 6, 11-16. [CrossRef] [PubMed]

6. Ghelardini, C.; Di Cesare Mannelli, L.; Bianchi, E. The pharmacological basis of opioids. Clin. Cases Miner. Bone Metab. 2015, 12, 219-221. [CrossRef] [PubMed] 
7. Zadina, J.E.; Martin-Schild, S.; Gerall, A.A.; Kastin, A.J.; Hackler, L.; Ge, L.J.; Zhang, X. Endomorphins: Novel endogenous mu-opiate receptor agonists in regions of high mu-opiate receptor density. Ann. N. Y. Acad. Sci. 1999, 897, 136-144. [CrossRef] [PubMed]

8. Shulgin, A.T. Drugs of abuse in the future. Clin. Toxicol. 1975, 8, 405-456. [CrossRef] [PubMed]

9. Pasquinucci, L.; Iadanza, M.; Marrazzo, A.; Prezzavento, O.; Ronsisvalle, S.; Scoto, G.M.; Parenti, C.; De Luca, L.; Ronsisvalle, G. New benzomorphan derivatives of MPCB as MOP and KOP receptor ligands. Pharmazie 2007, 62, 813-824. [CrossRef] [PubMed]

10. Metcalf, M.D.; Aceto, M.D.; Harris, L.S.; Woods, J.H.; Traynor, J.R.; Coop, A.; May, E.L. The influence of esters and carboxylic acids as the N-substituent of opioids. Part 1: Benzomorphans. Bioorg. Med. Chem. 2008, 16, 869-873. [CrossRef] [PubMed]

11. May, E.L.; Jacobson, A.E.; Mattson, M.V.; Traynor, J.R.; Woods, J.H.; Harris, L.S.; Bowman, E.R.; Aceto, M.D. Synthesis and in vitro and in vivo activity of $(-)-(1 R, 5 R, 9 R)-$ and (+)-(1S,5S,9S)-N-Alkenyl-, -N-Alkynyl-, and -N-Cyanoalkyl-5, 9-dimethyl-2'-hydroxy-6,7-benzomorphan homologues. J. Med. Chem. 2000, 43, 5030-5036. [CrossRef] [PubMed]

12. Turnaturi, R.; Marrazzo, A.; Parenti, C.; Pasquinucci, L. Benzomorphan scaffold for opioid analgesics and pharmacological tools development: A comprehensive review. Eur. J. Med. Chem. 2018, 148, 410-422. [CrossRef] [PubMed]

13. Dortch-Carnes, J.; Potter, D.E. Bremazocine: A kappa-opioid agonist with potent analgesic and other pharmacologic properties. CNS Drug Rev. 2005, 11, 195-212. [CrossRef] [PubMed]

14. Pasquinucci, L.; Prezzavento, O.; Marrazzo, A.; Amata, E.; Ronsisvalle, S.; Georgoussi, Z.; Fourla, D.D.; Scoto, G.M.; Parenti, C.; Aricò, G.; et al. Evaluation of N-substitution in 6,7-benzomorphan compounds. Bioorg. Med. Chem. 2010, 18, 4975-4982. [CrossRef] [PubMed]

15. Parenti, C.; Turnaturi, R.; Aricò, G.; Marrazzo, A.; Prezzavento, O.; Ronsisvalle, S.; Scoto, G.M.; Ronsisvalle, G.; Pasquinucci, L. Antinociceptive profile of LP1, a non-peptide multitarget opioid ligand. Life Sci. 2012, 90, 957-961. [CrossRef] [PubMed]

16. Pasquinucci, L.; Parenti, C.; Turnaturi, R.; Aricò, G.; Marrazzo, A.; Prezzavento, O.; Ronsisvalle, S.; Georgoussi, Z.; Fourla, D.D.; Scoto, G.M.; et al. The benzomorphan-based LP1 ligand is a suitable MOR/DOR agonist for chronic pain treatment. Life Sci. 2012, 90, 66-70. [CrossRef] [PubMed]

17. Parenti, C.; Turnaturi, R.; Aricò, G.; Gramowski-Voss, A.; Schroeder, O.H.; Marrazzo, A.; Prezzavento, O.; Ronsisvalle, S.; Scoto, G.M.; Ronsisvalle, G.; et al. The multitarget opioid ligand LP1's effects in persistent pain and in primary cell neuronal cultures. Neuropharmacology 2013, 71, 70-82. [CrossRef] [PubMed]

18. Pasquinucci, L.; Turnaturi, R.; Aricò, G.; Parenti, C.; Pallaki, P.; Georgoussi, Z.; Ronsisvalle, S. Evaluation of $\mathrm{N}$-substituent structural variations in opioid receptor profile of LP1. Bioorg. Med. Chem. 2016, 24, 2832-2842. [CrossRef] [PubMed]

19. Turnaturi, R.; Parenti, C.; Prezzavento, O.; Marrazzo, A.; Pallaki, P.; Georgoussi, Z.; Amata, E.; Pasquinucci, L. Synthesis and Structure-Activity Relationships of LP1 Derivatives: N-Methyl-N-phenylethylamino Analogues as Novel MOR Agonists. Molecules 2018, 23, E677. [CrossRef] [PubMed]

20. Pasquinucci, L.; Turnaturi, R.; Prezzavento, O.; Arena, E.; Aricò, G.; Georgoussi, Z.; Parenti, R.; Cantarella, G.; Parenti, C. Development of novel LP1-based analogues with enhanced delta opioid receptor profile. Bioorg. Med. Chem. 2017, 25, 4745-4752. [CrossRef] [PubMed]

21. Accolla, M.L.; Turnaturi, R.; Sarpietro, M.G.; Ronsisvalle, S.; Castelli, F.; Pasquinucci, L. Differential scanning calorimetry approach to investigate the transfer of the multitarget opioid analgesic LP1 to biomembrane model. Eur. J. Med. Chem. 2014, 77, 84-90. [CrossRef] [PubMed]

22. Vandormael, B.; Fourla, D.D.; Gramowski-Voss, A.; Kosson, P.; Weiss, D.G.; Schröder, O.H.; Lipkowski, A.; Georgoussi, Z.; Tourwé, D. Superpotent [Dmt $\left.{ }^{1}\right]$ dermorphin tetrapeptides containing the 4-aminotetrahydro-2-benzazepin-3-one scaffold with mixed $\mu / \delta$ opioid receptor agonistic properties. J. Med. Chem. 2011, 54, 7848-7859. [CrossRef] [PubMed]

23. Papakonstantinou, M.P.; Karoussiotis, C.; Georgoussi, Z. RGS2 and RGS4 proteins: New modulators of the K-opioid receptor signaling. Cell Signal. 2015, 27, 104-114. [CrossRef] [PubMed]

24. Camarda, V.; Calò, G. Chimeric G proteins in fluorimetric calcium assays: Experience with opioid receptors. Methods Mol. Biol. 2013, 937, 293-306. [CrossRef] [PubMed]

25. Georgoussi, Z.; Zioudrou, C. Effect of delta-opioid antagonists on the functional coupling between opioid receptors and G-proteins in rat brain membranes. Biochem. Pharmacol. 1993, 45, 2405-2410. [CrossRef] 
26. Guerrini, R.; Calò, G.; Rizzi, A.; Bianchi, C.; Lazarus, L.H.; Salvadori, S.; Temussi, P.A.; Regoli, D. Address and message sequences for the nociceptin receptor: A structure-activity study of nociceptin-(1-13)-peptide amide. J. Med. Chem. 1997, 40, 1789-1793. [CrossRef] [PubMed]

27. Bradford, M.M. A rapid and sensitive method for the quantitation of microgram quantities of protein utilizing the principle of protein-dye binding. Anal. Biochem. 1976, 72, 248-254. [CrossRef]

28. Prezzavento, O.; Arena, E.; Parenti, C.; Pasquinucci, L.; Aricò, G.; Scoto, G.M.; Grancara, S.; Toninello, A.; Ronsisvalle, $\mathrm{S}$. Design and synthesis of new bifunctional sigma-1 selective ligands with antioxidant activity. J. Med. Chem. 2013, 56, 2447-2455. [CrossRef] [PubMed]

29. Georgoussi, Z.; Merkouris, M.; Mullaney, I.; Megaritis, G.; Carr, G.; Zioudrou, C.; Milligan, G. Selective interactions of the $\mu$-opioid receptors with pertussis toxin-sensitive $G$ proteins: Involvement of the third intracellular loop and the C-terminal tail in coupling. Biochem. Biophys. Acta 1997, 1359, 263-274. [CrossRef]

30. Morou, E.; Georgoussi, Z. Expression of the third intracellular loop of the delta-opioid receptor inhibits signaling by opioid receptors and other $\mathrm{G}$ protein-coupled receptors. J. Pharmacol. Exp. Ther. 2005, 315, 1368-1379. [CrossRef] [PubMed]

(C) 2018 by the authors. Licensee MDPI, Basel, Switzerland. This article is an open access article distributed under the terms and conditions of the Creative Commons Attribution (CC BY) license (http://creativecommons.org/licenses/by/4.0/). 